\title{
SPONTANEOUS VENTRICULAR RUPTURE IN HYDROCEPHALUS, WITH SUBTENTORIAL CYST FORMATION
}

\author{
BY
}

\author{
JOE PENNYBACKER and DOROTHY S. RUSSELL *
}

(From the Nuffield Department of Surgery, Oxford)

\author{
(ReCEIVEd 9TH APRIL, 1943)
}

The anatomical features of hydrocephalus are fairly well known, and a growing knowledge of the pathology suggests that in most if not all cases the ventricular dilatation can be explained by obstruction to the circulation of the cerebro-spinal fluid. It is not always easy to identify the site or cause of the obstruction, but a common place is in the narrows of the midbrain where the aqueduct may be compressed by a benign proliferation of the subependymal glia or by a tumour of the brain stem, pineal gland or vermis cerebelli. As the prognosis and treatment differ considerably in these various conditions, we commonly look to ventriculography for help in diagnosis. For various reasons, the interpretation of air shadows in this region is not always easy, or indeed possible, and we feel that any additional information about the pathological possibilities should be of importance.

This report deals chiefly with two cases of hydrocephalus in which the dilatation of the lateral ventricles was accompanied by rupture of the wall of the ventricle in the region of the vestibule, and the formation of a cyst-like space under the tentorium communicating with the lateral ventricle. The site of the rupture was identical in the two cases, and the ventriculographic appearances were similar. In both cases the hydrocephalus resulted from aqueduct obstruction, in one by proliferation of the subependymal glia and in the other by a fibrillary astrocytoma of the brain stem. We have also included the pathological report of a case of hydiccephalus due to adhesive arachnoiditis in which an early stage in the development of this process was seen.

Our interest in this abnormality began with an earlier case of stenosis of the aqueduct which had produced great dilatation of the third ventricle. The distended suprapineal recess protruded as a cyst-like swelling beneath the splenium, insinuating itself between the lower surfaces of the occipital lobes, and the upper surface of the cerebellum. Since then we have seen such dilatations in ventriculograms on a number of occasions and had come to regard the presence of a large suprapineal recess as evidence for an intrinsic lesion of the brain stem (benign stricture or tumour) as opposed to an extrinsic lesion such as a tumour of the superior vermis or of the pineal gland. The recess may be dilated in cases of obstruction in the distal part of the fourth ventricle too, but in these cases the aqueduct and fourth ventricle are generally dilated and it is fairly easy to demonstrate them in ventriculograms. In our first case, a large air-shadow beneath the tentorium was thought to be such a dilated suprapineal recess until it was shown at necropsy to be in communication with the lateral and not with the third ventricle.

\section{Case Reports}

Case 1. J.H. (R.I. 11851), a girl of 16 years, was admitted to the Radcliffe Infirmary on $4 / 11 / 40$, complaining of headache. For two years she had been subject to attacks of headache lasting for four or five hours, occurring once or twice a month, with good health in the intervals. She occasionally vomited with the headaches, and for a year she had often been aware of a rhythmical noise in the head (which it was found could be stopped by compressing one or other carotid artery in the neck). The increasing frequency and severity of the headaches brought her to hospital; there were no other symptoms on direct enquiry.

On examination she was a healthy-looking girl normally developed and rather above the average intelligence. The skull was $54 \mathrm{~cm}$. in circumference, slightly larger than normal. There was bilateral papillœdema, 3 D., but the visual acuity and fields were normal, except for slight enlargement of the blind spots. The pupils and ocular movements were normal, and there were no definite abnormalities in the examination of the rest of the nervous system. The spinal fluid pressure was $270 \mathrm{~mm}$., and the fluid was normal on analysis. X-rays of the skull showed some convolutional thinning of the vault, early separation of the sutures, and some erosion of the sella turcica.

Comment.-This was thus a case of increased intracranial pressure with no definite localizing signs. Ventriculography revealed symmetrical dilatation of the lateral ventricles, and of the third ventricle with what was interpreted as a dilated suprapineal pouch (Fig. 1). The aqueduct could not be visualized distal to its upper end, and no air had got through to the fourth ventricle or cisterna magna. The appearances were regarded as being due to a stricture of the aqueduct, probably caused by proliferation of the subependymal glia.

At operation on the same day, 8/11/40, an incision was made in the lamina terminalis, by way of the right sub-frontal approach. The post-operative 
period was uneventful, and she was discharged from hospital on $28 / 11 / 40$ free from symptoms. The osteoplastic flap was not tense, the spinal fluid pressure was $160 \mathrm{~mm}$., and the papillœdema had virtually subsided.

She was well for two months, when she had a bout of pain in the right upper jaw which was eased by a dental extraction. At this time, the decompression

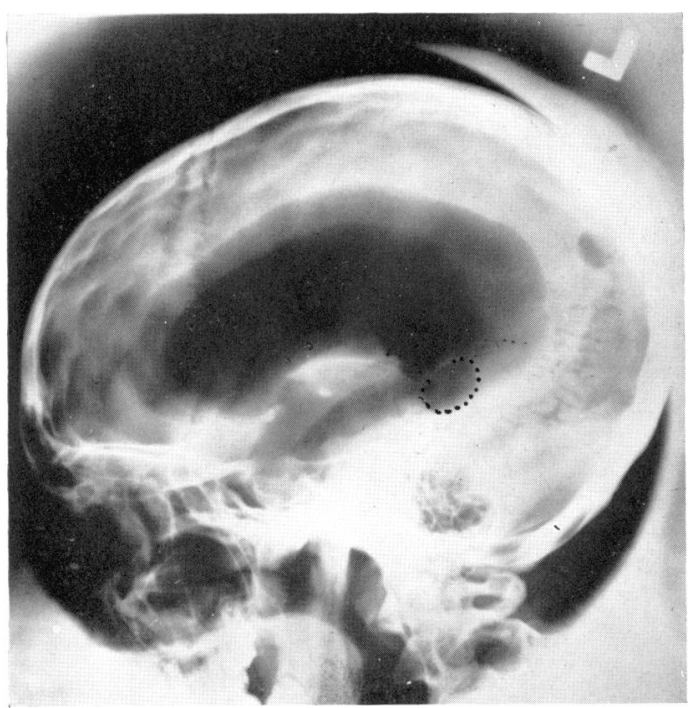

Fig. 1.-Case 1-First ventriculogram, showing small pouch below lateral ventricle.

was apparently flat, but as the pathological diagnosis had not been verified, we advised a course of deep X-ray therapy to the region of the brain stem. From the beginning of the treatment the decompression became more tense, the flap bulged, she developed a gradually progressive left hemiplegia, became very drowsy and incontinent. In that state she was readmitted on $6 / 5 / 41,6$ months after operation.

Clearly the fistula had not been effective, or, if it

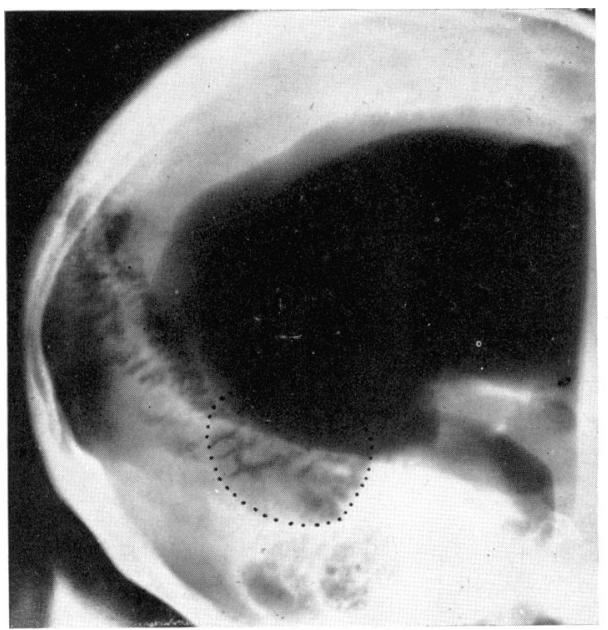

had, the lesion had progressed beyond the limit of compensation. The ventriculogram was repeated, and the ventricular dilatation was even more pronounced. The right frontal horn bulged with the decompression; but more striking was a large cystic collection under the anterior border of the tentorium (Fig. 2). This was an advanced stage of what had been seen six months earlier and had been regarded as a dilated suprapineal recess. Again no air was seen distal to the upper reaches of the aqueduct.

As the anterior fistula did not seem to have been effective, and as the presence of this pouch in the posterior fossa seemed to be an argument against a neoplasm in the cerebellum, we decided to open the pouch from behind, a sort of posterior ventriculostomy, hoping that a fistula between the third ventricle and the cisterna ambiens might be effective where one between the third ventricle and cisterna chiasmaticus had failed. By the usual cerebellar exposure, and retraction of the left cerebellar lobe downward from the tentorium, the cyst-like dilatation was seen and incised (Fig. 3). Although it was possible to explore the interior of this cavity by direct vision, the relations were confusing and anatomical landmarks could not be identified with certainty.

Again the post-operative phase was encouraging. Her general condition improved, the hemiplegia lessened, and the intracranial pressure, as judged by recession of the decompression and normal cerebrospinal fluid pressure, was satisfactory. On the morning of the ninth post-operative day she had two Jacksonian epileptic attacks down the left side of the body in quick succession, and died suddenly.

\section{Pathological Examination}

Summary of Necropsy.-Congestion of lungs. Internal hydrocephalus. Gliosis of iter. Operation: Ventriculostomy.

Bilateral pleural effusion ( $\frac{1}{2}$ pint each side). Congestion of lungs; collapse of basal portions of

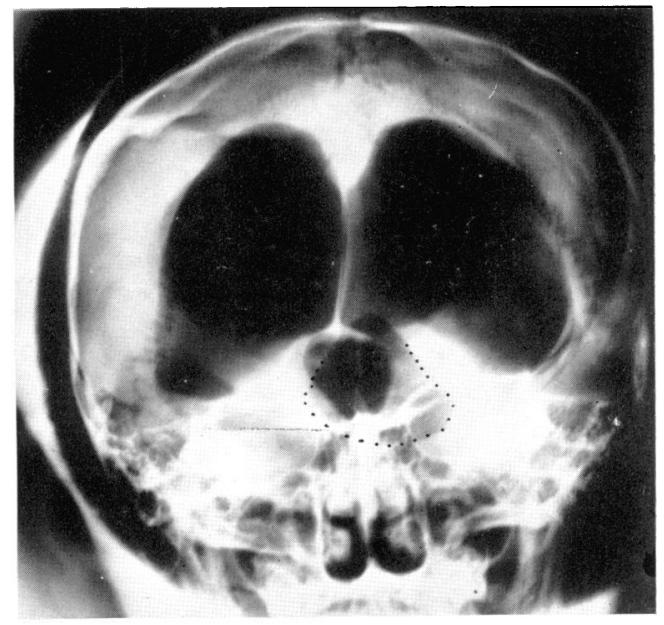

Fig. 2.-Case 1-Ventriculograms made 6 months later, showing increased size of cyst. 


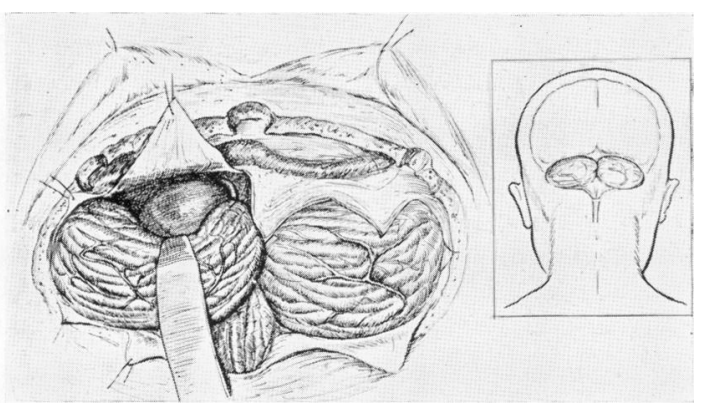

Fig. 3.-Case 1-Operation sketch.

lungs. Slight fibrous thickening of base of cusps of mitral valve. Calculous material in pelvis of left kidney; no further atnormality in abdominal organs. A few small cysts in colloidal thyroid gland.

Brain.-Macroscopic.-The cerebral hemispheres were considerably but unevenly expanded, the right frontal lobe bulging greatly at the site of the old craniotomy, which measured 8 by $4.5 \mathrm{~cm}$. Apart from this area the meninges over the convexities of the brain appeared normal, except for slight subdural and subarachnoid hæmorrhage over the inferior surface of the right $\rightleftharpoons$ temporo-occipital region. In the meninges over the quadrigeminal plate was an empty space which measured $1.9 \mathrm{~cm}$. from above down by $1.1 \mathrm{~cm}$. in the mid-sagittal plane by about $2 \cdot 2 \mathrm{~cm}$. from side to side, and was bounded dorsally and laterally by a grey translucent fibrous membrane continuous with the arachnoid membrane. The roof of the space arched over the gap between the splenium and the anterior border of the vermis, lying $\frac{\sigma}{}$ beneath but in close relationship to the pineal body and $\mathbb{D}$ the great vein of Galen (Fig. 4). An operative perforation, measuring $0.7 \mathrm{~cm}$. in diameter, occupied the left $\mathrm{o}$ side of the membrane. Internally the membrane appeared smooth and was sealed off everywhere from the adjacent cerebrospinal spaces, except at one point where it communicated with the left lateral ventricle by an orifice measuring 0.8 by $0.5 \mathrm{~cm}$. This orifice was situated in the hinder part of the body of the ventricle, in the thin lamina of white matter that lies posterior to the fornix and medial to the hippocampal gyrus (Fig. 4). Its borders were smooth and rounded. At the same position $\vec{j}$ in the right lateral ventricle was a dimple of similar size, $N$ but with no perforation in its depths. A ventriculostomy $\omega_{\infty}$

(Top portion).
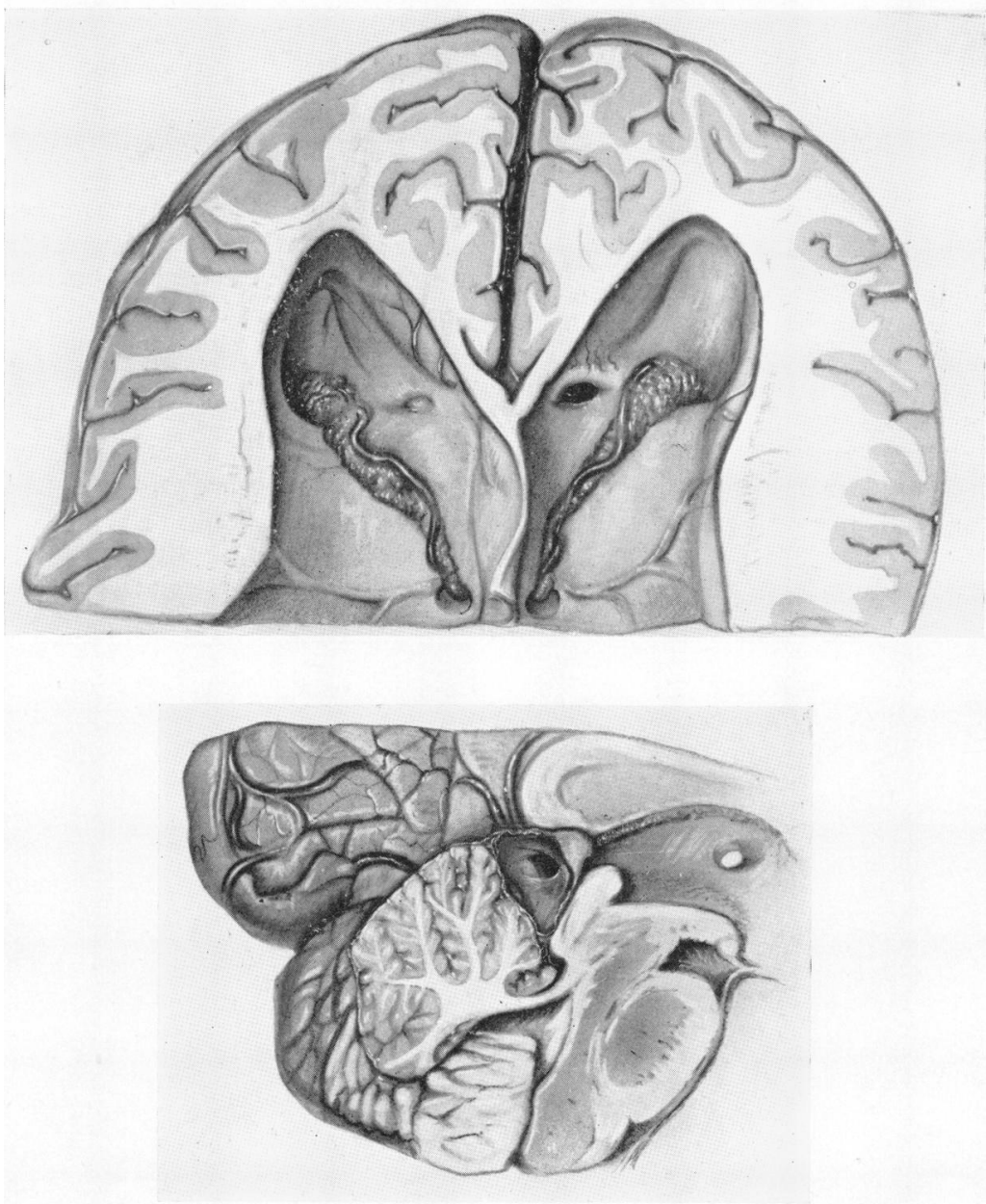

Fig. 4.-Case 1-Sketch showing relations of cyst, aperture into left ventricle, and thinning of the corresponding part of the right ventricular wall. 
opening, measuring 0.4 by $0.3 \mathrm{~cm}$., was present in the supraoptic recess. Delicate fibrous adhesions were attached to the borders of this opening, and the rupture of some of these during removal of the brain was followed by a gush of clear cerebrospinal fluid.

There was considerable dilatation of the third and lateral ventricles, the foramina of Monro being $0.8 \mathrm{~cm}$. in diameter on either side. The right frontal horn was more voluminous than the left. The septum pellucidum was considerably fenestrated and the grey commissure elongated $(1.2 \mathrm{~cm}$.). The ependyma everywhere appeared thick and corrugated, but was smooth, glistening, and free from granulation. The choroid plexuses appeared normal. No lumen was visible throughout the anterior $0.6 \mathrm{~cm}$. of the iter. The fourth ventricle was normal.

Microscopic.-The mid-brain was divided into four slices in the coronal plane and these, with the anterior end of the vermis in the mid-sagittal plane, the posterolateral border of the orifice in the left ventricle and portions of the third and fourth ventricles in the coronal plane were embedded in paraffin wax. Sections were stained with Ehrlich's hæmatoxylin and eosin, Weigert's iron hæmatoxylin and Van Gieson's mixture and with phosphotungstic acid hæmatoxylin.

The lumen of the iter is subdivided into a number of small irregular channels by a dense cellular and fibrillary gliosis which extends into, without expanding, the quadrigeminal plate, diminishing towards its dorsal surface but becoming intensified again in the marginal glia. The gliosis encroaches ventrolaterally on the borders of the nucleus of the third nerve on the left, but the right nucleus is free. The greater part of the iter is so involved, and even where at either end of its course the lumen is of normal outline there is excessive thickening of the dorsal subependymal glia extending into the quadrigeminal plate. In most places the subdivisions of the lumen are lined with a well-preserved, ciliated ependyma; a few areas are denuded. A few blood vessels in and near the hyperplastic glial tissue show slight cuffing with small lymphocytes.

The border of the orifice in the left lateral ventricle is formed by an everted tapering fringe of the subependymal glia which is of normal appearance. The ependyma covering the fringe and the adjacent wall of the ventricle is absent in many places. Over some of the denuded areas there are groups of degenerating leucocytes and macrophages containing red corpuscles; occasional macrophages containing iron pigment occupy the superficial layers of subependymal glia. The adjacent leptomeninges are thickened by young fibrous tissue and sparsely infiltrated with lymphocytes, desquamated arachnoid cells, and neutrophil leucocytes. At a little distance from the orifice, corresponding to the margin of the space in the cisterna ambiens, there is an abrupt change to normal. A similar thickening and infiltration affects the meninges walling this space over the quadrigeminal plate and the anterior border of the vermis.

Short strips of the ependyma of the third ventricle are missing in some areas, and in other places there is focal degeneration and necrosis of a few contiguous cells, such points often being overlaid by a small cluster of macrophages containing red corpuscles together with degenerating polymorphonuclear leucocytes and eosinophil cellular debris. At some of the denuded spots the subependymal glia protrudes slightly towards the lumen. The appearances suggest an early stage of granular ependymitis. In the fourth ventricle the ependyma is of normal appearance. The leptomeninges over the brain stem are sparsely infiltrated with desquamated arachnoid cells and neutrophil leucocytes, and contain some free red corpuscles.

Summary.-The hydrocephalus in this case was due to gliosis of the iter. As in other similar cases there was no histological evidence pointing to the rtiology of this condition. The scanty perivascular lymphocytic infiltration seen in a few vessels in and near the gliosis was probably in direct association with the slight chronic inflammation of the adjacent meninges. This infiltration doubtless resulted from breaking down of tissue at the site of the communication between the left lateral ventricle and the leptomeninges over the quadrigeminal plate. Subsequent operative procedures, with the freeing of red corpuscles and small amounts of cellular debris into the cerebrospinal fluid promoted a slight meningeal and ependymal reaction as seen over the brain stem and the lining of the third ventricle respectively.

Case 2. B.B. (R.I. 16954), a female aged 20 years, was admitted on 25741 , complaining of severe headache. For two years she had been subject to attacks of headache and vomiting, coming on in the early morning, lasting for several hours, and then clearing up completely. These headaches occurred almost daily, with rare intervals of freedom up to a fortnight, and they made it necessary for her to give up her career of nursing. A short time before admission she had had two or three especially severe attacks in which the headache was accompanied by a transient loss of contact with her surroundings, a feeling of weakness of all her limbs, and some difficulty in speaking, which was probably a dysarthria. The only other symptom of significance was in connection with menstruation: the menarche occurred at 16 years and she had had only three scanty periods from that time.

On examination, she was a tall young woman with the facial appearance of mild acromegaly, but there was no enlargement of the hands or feet. The secondary sexual characteristics were normally developed. She was alert and intelligent, and during the week of observation in hospital she complained of very severe headache, and vomited on three occasions. There was no enlargement of the skull. The sense of smell was impaired in each nostril, but it was not lost. There was bilateral papill dema of three diopters, but the visual acuity and fields were normal, except for slight enlargement of the blind spots. The pupils and ocular movements were normal, but there were a few nystagmoid jerks at the extremes of lateral deviation. There was no definite weakness, tremor, or ataxy in her face, trunk, or limbs. The reflexes were all normal and there was no sensory defect. Lumbar puncture revealed clear, colourless spinal fluid under a pressure of $300 \mathrm{~mm}$. The fluid contained $30 \mathrm{mgm}$. of protein and no cells. X-rays of the skull showed some convolutional thinning, early separation of the sutures, and gross erosion of the sella turcica.

Comment.-As in the first case, the problem was one of increased intracranial pressure without localizing signs, and ventriculography revealed gross ventricular dilatation with a large pouch extending backwards under the tentorium (Fig. 5). No air was seen distal to the upper part of the aqueduct.

This appearance was recognized as being similar to that described in Case 1, and the same kind of procedure was decided on-i.e., cerebellar decompression and incision of the cyst below the tentorium. This operation was done under general anæsthesia without incident. She died seven hours later from a large extradural hiemorrhage over the right cerebral hemisphere.

\section{Pathological Examination}

Summary of Necropsy.-Extradural hæmatoma. Internal hydrocephalus. Astrocytoma of mid- 

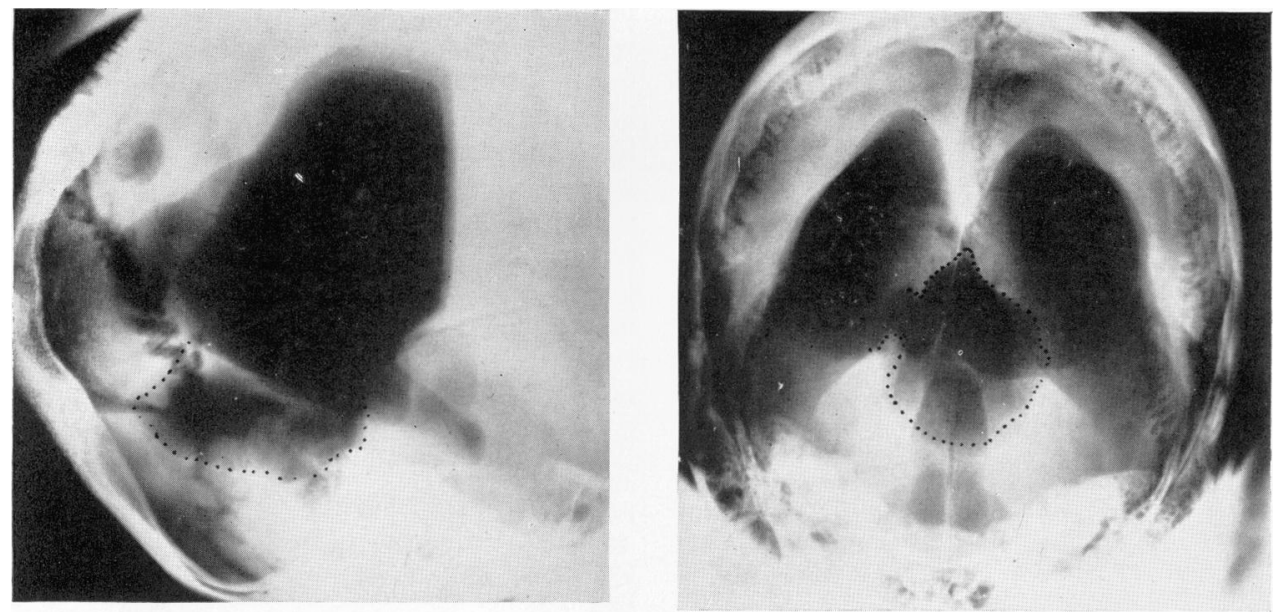

Fig. 5.-Case 2-ventriculograms showing outlines of cyst below tentorium and aperture into left ventricle.

brain. Operations: suboccipital craniotomy and ventriculography.

Recent hæmatoma, measuring $12 \mathrm{~cm}$. anteroposteriorly by $9 \mathrm{~cm}$. above down and up to $2.5 \mathrm{~cm}$. deep between dura and cranium over right frontoparietal region, apparently caused by rupture of vein emerging from dura in region of one of the lacunæ laterales. Slight flattening from above downwards of otherwise normal pituitary body. No further abnormalities in endocrine system. A few atretic follicles and no corpora lutea in ovaries. Atrophy of endometrium in rather small uterus (body $3 \mathrm{~cm}$. long; cervix $2.8 \mathrm{~cm}$. long). Slight congestion and parenchymatous degeneration of liver. A few acute erosions $(1.5$ by $1 \mathrm{~cm}$.) in œsophagus. Slight atheroma involving mitral valve and aortic ring. Slight dilatation and hypertrophy of both ventricles of heart. Subendocardial hæmorrhages in left ventricle. Moderate congestion and œdema of lungs. A well-developed, slightly adipose woman.

Brain.-Macroscopic.-The hæmatoma had caused great flattening of the right cerebral convexity, but the left cerebrum was of good shape, its contours being full and rounded. The floor of the third ventricle formed a translucent balloon filling the interpeduncular space and measuring 3.0 by $2.2 \mathrm{~cm}$. There was a cerebellar pressure-cone $2 \cdot 0 \mathrm{~cm}$. long. Over the quadrigeminal plate the arachnoid membrane was elevated to form a space, about $3.0 \mathrm{~cm}$. in diameter, which extended over the anterior end of the vermis for a distance of about $2 \mathrm{~cm}$. The membrane contained several oval openings, corresponding to those made at operation. Elsewhere the space appeared to be sealed off from the cerebrospinal pathway, except where an oval orifice, 1.0 by $0.7 \mathrm{~cm}$., led into the cavity of the left lateral ventricle in a position identical with that observed in Case 1 (Fig. 6). There was no corresponding opening or dimple on the right side, but the tissue here was thin and translucent. The margins of the orifice were smooth and rounded, except along its medial border, which was occupied by a crescentic flange of translucent tissue up to about $2 \mathrm{~mm}$. wide. Both lateral ventricles were equally and considerably dilated, the foramina of Monro measuring 1.5 by $1 \mathrm{~cm}$. The septum pellucidum was fenestrated. The ependyma everywhere was somewhat thickened and discoloured by hæmolytic staining. In places there were small abrasions and recent subependymal hæmorrhages resulting from puncture wounds, especially in the occipital horns.

On section the quadrigeminal plate was expanded into a smooth, dome-shaped mass, about $1.5 \mathrm{~mm}$. dorsiventrally and $2 \mathrm{~cm}$. from side to side, of poorly defined rubbery milky-white tissue. The mass involved the right side rather more than the left. The whole length of the iter was greatly compressed and displaced ventrally and to the left. The pineal body was intact and lay in the dorsal wall of the meningeal space over the mid-brain. The fourth ventricle was normal.

Microscopic.-The tissue examined and stains used were as in Case 1. The quadrigeminal plate is greatly expanded by a tumour composed of fibrillary astrocytes which form, in many places, interlacing bundles of elongated bipolar cells and elsewhere less dense areas in which small stellate cells form small groups separated by a feltwork of their interlacing processes. In the depths of the mid-brain the tissue is often more cellular, the nuclei being in general larger and uneven in size. A few multinucleate cells are present. The borders of the tumour are moderately defined through the circumferential arrangement of the cells in these parts. There is extensive invasion by tumour cells of the leptomeninges over the dorsal surface of the mid-brain and a similar invasion of the Virchow-Robin space of some of the perforating vessels in this region. On the left ventrolateral border of the tumour the aqueduct is deformed to an oblique slit. Its ependyma has been partly replaced by tumour cells.

The appearances of the orifice in the left lateral ventricle are similar to those described in Case 1. The corresponding imperforate area in the right ventricle is occupied by a lamina, about $0.6 \mathrm{~mm}$. thick, of ependyma and subependymal glia. The appearances of the nervous tissues are normal, apart from loss of the ependymal cells in many areas. There is slight fibrosis of the adjacent meninges with a considerable collection of red corpuscles, fibrin and few neutrophil leucocytes in the meshes of the pia. The leptomeninges forming the wall of the cystic space over the mid-brain show fibrous thickening and sparse infiltration with lymphocytes and desquamated cells as in Case 1 . There is, in addition, some infiltration with neutrophil leucocytes. Over the ventral aspect of the brain stem the reaction is limited to slight focal leucocytic infiltration.

Summary.-This case resembles Case 1 in the formation of an opening between the left lateral ventricle and the leptomeninges as a mechanical consequence of internal hydrocephalus. The communication was found at the same site, and the 


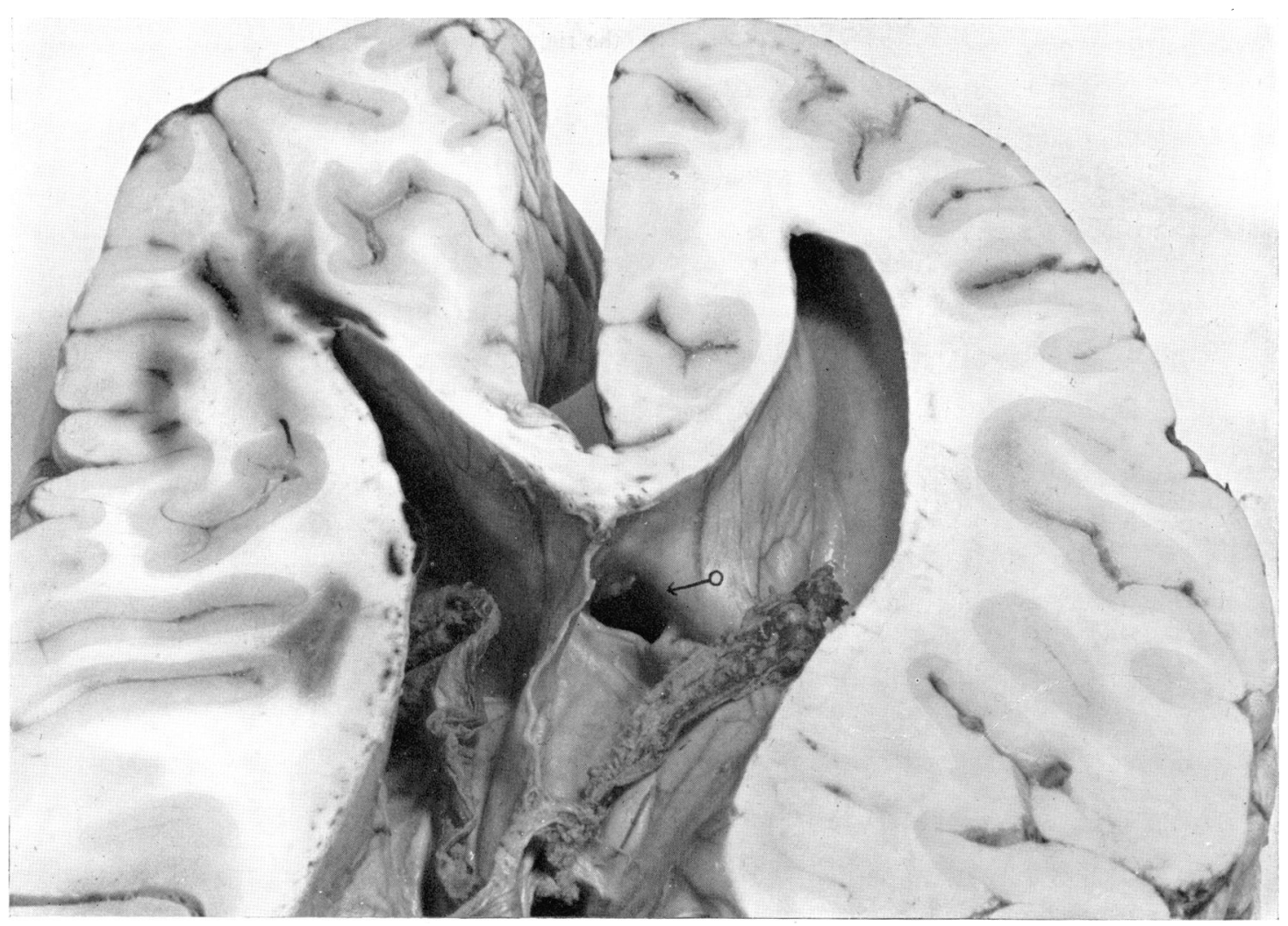

Fig. 6.-Case 2-Arrow indicates aperture in floor of left ventricle.

corresponding area in the right ventricle was of translucent thinness. The cause of the hydrocephalus here was a fibrillary astrocytoma of the quadrigeminal plate which deformed the iter; in Case 1 a gliosis of the iter was responsible. In the literature these two types of lesion have often been confused, but, though we have insufficient evidence to deny categorically the neoplastic character of aqueductal gliosis, there are certain features on which we may base a distinction in the present two cases.

1. Macroscopic expansion and deformity of the mid-brain.- This was absent in Case 1, but a definite feature in Case 2.

2. Subdivision and displacement of the aqueduct.In Case 1 subdivision was conspicuous, but the aqueduct occupied its normal position in the midline; in Case 2 the aqueduct was displaced and deformed, but not subdivided.

3. Cytological features of neoplastic growth were not seen in Case 1. In Case 2 we observed invasion by fibrillary astrocytes of the meninges and VirchowRobin spaces of blood vessels, also variations in the morphology of the cells with occasional multinucleate giant cells.

The distinctions indicated in 1 and 2 are probably of greater value than those in 3 .

Case 3. G.H. (R.I. 19190), a female child aged three years, was admitted on 31141 , suffering from advanced hydrocephalus which dated from early infancy and was at first thought to be congenital. There was a story of a febrile illness at the age of three weeks, and although the details were not sufficiently clear to establish its nature with certainty, it probably was a meningeal inflammation. The child was brought to hospital because of progressive enlargement of the head, and inability to sit or stand. She was a fat, healthy-looking child, with a very large head, $61.5 \mathrm{~cm}$. in circumference. Her mental development seemed to be normal as judged by speech and behaviour. There was low-grade papillœdema with normal visual acuity and full fields. There were no abnormalities in the pupils or ocular movements, nor in the other functions subserved by the cranial nerves. The limbs were slightly hypertonic and generally weak, but there was no definite ataxy. All the tendon reflexes were brisk, and both plantar responses were extensor. There seemed to be no disturbance of sensibility to pin-prick and cotton wool. The spinal fluid pressure was $240 \mathrm{~mm}$. and the fluid contained $60 \mathrm{mgm}$. protein and 2 cells. $\mathrm{X}$-rays of the skull showed gross separation of the sutures. A ventriculogram revealed a gross dilatation of the whole ventricular system including the 4 th ventricle.

Comment.-It was thought that the hydrocephalus resulted from adhesive arachnoiditis which had occluded the foramina in the fourth ventricle. At operation on the same day an incision was made in the lamina terminalis by the right frontal approach. The post-operative period was marked by hyperpyrexia, tachycardia, and other features seen after ventriculography in cases of advanced hydrocephalus and she died on the sixth day.

\section{Pathological Examination}

Summary of Necropsy.-Internal hydrocephalus. Chronic meningitis. Operation: Ventriculostomy. 
There were no significant changes in chest or abdomen. The dura was firmly sutured over a craniotomy opening, 4.5 by $3 \mathrm{~cm}$., in the right frontal region. The anterior fontanelle was patent, measuring $12 \mathrm{~cm}$. from side to side and $9 \mathrm{~cm}$. anteroposteriorly. The skull was greatly expanded and translucent, the bone being from $0 \cdot 2$ to $0.3 \mathrm{~cm}$. thick. A little muco-pus was present in the left middle ear.

Brain.-Macroscopic.-Both cerebral hemispheres were greatly and symmetrically expanded and their meninges engorged. There was slight diffuse subarachnoid hæmorrhage over the occipital lobes corresponding to the

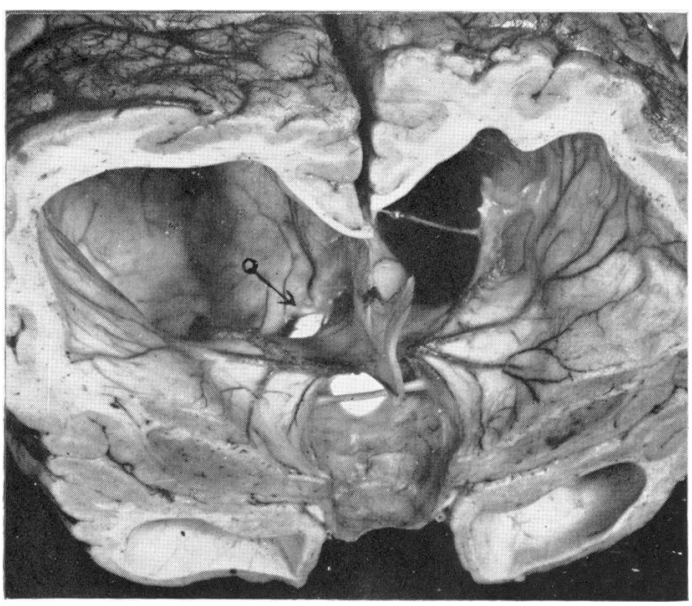

Fig. 7.-Case 3-Arrow indicates translucent area in floor of right lateral ventricle.

burr-holes made for ventriculography. A patent ventriculostomy opening, measuring $0.7 \mathrm{~cm}$. in diameter, occupied the anterior wall of the third ventricle. There was grey gelatinous thickening of the leptomeninges over the whole of the brain stem, forming a pouch with welldefined borders over each foramen of Luschka. In the basal and interpeduncular cisterns and the proximal parts of the Sylvian fissures a similar thickening was accompanied by brownish discoloration. The arachnoid membrane roofing the cisterna magna was firmly adherent to the dura mater near the mid-line, its margins being thickened and slightly opaque. This cistern was greatly expanded, measuring 3 by 2 by $1.5 \mathrm{~cm}$. in depth, and the foramen of Majendie was so large $(1.1$ by $0.7 \mathrm{~cm}$.) that the hind-end of the aqueduct could be viewed through it. The whole of the ventricular system was greatly expanded, the aqueduct measuring 0.7 by $0.5 \mathrm{~cm}$. in cross-section. The right lateral ventricle however was slightly larger than the left and the latter was incompletely divided, at the level of the vestibule, by a falciform septum with a translucent, slightly fenestrated free medial border which extended from the dorsal surface of the choroid plexus to unite with the roof. This plexus was smooth, grey, and opaque as though embedded in fibrous tissue, and from it extended a thin filament of similar grey tissue uniting with the medial wall of the ventricle (Fig. 7). A similar filament traversed the cavity of the third ventricle parallel with the anterior and grey commissures. Apart from a fine morocco-leather granularity of the ependyma over the basal ganglia the walls of the ventricle were smooth, ivory white, and corrugated. In the right lateral ventricle the site of the orifice leading into the leptomeninges observed in Cases 1 and 2 was occupied by a sharply defined oval translucent membrane, measuring about 1 by $0.6 \mathrm{~cm}$. This was rendered conspicuous in photographing the specimen by placing a bright light behind it (Fig. 7).
Microscopic.-The translucent area in the hind-part of the right ventricle, illustrated in Fig. 7, is formed by a membrane, from 87.5 to $105 \mu$ thick, of fibrillary glia. The ependyma has been lost from its ventricular surface and is interrupted over the adjacent hippocampal gyrus. The leptomeninges covering the outer aspect of the membrane are normal apart from a sparse infiltration with desquamated arachnoid cells, lymphocytes and a few neutrophil leucocytes.

The septum in the left lateral ventricle is composed of vascularized neuroglial tissue devoid of inflammatory infiltration except where it unites with the choroid plexus. The latter is embedded in a richly vascularized layer of neuroglial and collagenous tissue infiltrated with a few lymphocytes and small groups of macrophages many of which contain iron pigment. The anterior aspect of the lateral extremity of the septum and adjacent parietal wall of the ventricle are denuded of ependymal cells; a few short strips of these cells are present on the posterior surface of the septum where it approaches the ventricle wall.

The leptomeninges, especially the arachnoid membrane, over the brain stem and cisterna magna are thickened by fibrosis and infiltrated with numerous des- o quamated arachnoid cells, many of which have ingested red corpuscles, while a few contain granules of iron in pigment. Free red cells and sparser leucocytes and $\omega$ lymphocytes are also present. The arachnoid membrane $\infty$ over the cisterna magna is united to the dura by fibrous 을 tissue and here the arachnoid cells have proliferated to form sheets over the collagenous trabeculæ. The $c$ fibrosis does not extend however over the lateral lobes of the cerebellum, though phagocytic activity of the arachnoid cells is evident and is accompanied by a sparse infiltration with neutrophil leucocytes. There are numerous ependymal granulations in the lining of the fourth ventricle.

Summary.-Internal hydrocephalus is due, in this case, to chronic leptomeningitis of unknown ætiology. Birth trauma is unlikely to have been the cause since there is little evidence of old hæmorrhage; the small amounts of iron pigment present in the meninges over the brain stem, as well as the free and ingested red cells, may be attributed to the operation performed five days kefore death. It is possible that the febrile illness at the age of three weeks was a low-grade meningitis. The observation of expansion of the skull from this time onwards is in support of this view. There is insufficient evidence to indicate the origin of the septum and filaments within the ventricles.

The dilatation of the lateral ventricles was greater than in Cases 1 and 2, but the concomitant expansion of the skull probably prevented the intra-ventricular pressure from reaching the levels attained when the sutures are closed.

\section{General Comment}

These cases demonstrate an unusual sequel of hydrocephalus which may be commoner than we $\sigma$ have realized. Its importance lies chiefly in the interpretation of ventriculograms-and recognition of its nature should be of guidance in the $\stackrel{\oplus}{\oplus}$ surgical treatment of cases such as we have described.

The cystic collection in the leptomeninges was at first regarded as a diverticulum of the third ventricle $\frac{}{\mathbb{D}}$ until necropsy studies showed that it was in communication with the lateral ventricle. Further examination has shown that it is not a diverticulum

享

, 
of the ventricle, but a collection of cerebro-spinal fluid which escapes into the leptomeninges through a rupture of the wall of the ventricle. The rupture occurs in that part of the wall which is thinnest normally, i.e. in the medial angle of the collateral trigone (the floor of the ventricle) which lies between the forward-sweeping crus of the fornix, and the forceps major. In this region the ventricular wall is not supported by any appreciable thickness of white matter, nor by the basal ganglia, nor by any strong vascular network such as the choroid plexus. The effect of ventricular dilatation is to stretch this weak spot by increasing the angle between the crus of the fornix in front and the forceps major behind, and to make it even more thin. The rupture then takes place, and cerebrospinal fluid escapes beneath the pia. It is presumably the connection of the pia to the surface of the brain which limits the extent of the extracerebral collection of fluid to a cyst-like cavity. This enlarges into the most accessible space, i.e. in the incisura tentorii, and thus insinuates itself between the tentorium above, and the upper surface of the cerebellum and brain stem below. As it does so, it pushes the arachnoid before it, and the cyst can thus be said to be in the subarachnoid space. Passing through the incisura tentorii it occupies the upper part of the cisterna ambiens, and acting as a fluid plug it probably adds to the already existing obstruction by embarassing the return of cerebrospinal fluid from the posterior fossa to the supratentorial compartment. In neither of our cases did we detect any neurological signs which could be referred to direct pressure of the cyst on neighbouring structures.

That this process is not a diverticulum of the ventricle seems to be shown by our third case in which the wall of the ventricle was thinned to translucency, but there was no protrusion as would be expected in the early stages of the development of a diverticulum. The thinning may be bilateral but in our cases the rupture occurred only in one ventricle. Childe and McNaughton (1942) have recently reported a case of bilateral loculi of this nature which they speak of as ventricular diverticula, but they recognize the essential feature as being rupture of the ventricular wall. Sweet (1940) has also described a similar case discovered at autopsy, and he suggested the term " ventriculostium."

The treatment should be directed to the cause of the obstruction if that is possible. In cases of benign stricture of the aqueduct and neoplasm of the brain stem, we may have to be content with procedures which we hope will short-circuit the circulation of the cerebrospinal fluid around the obstruction. In many cases, anterior third ventriculostomy is effective and this is probably the procedure which should be tried first. If it is not effective, as in our first case, and subsequent ventriculograms show that the cyst is large enough to be accessible by a cerebellar approach, it seems reasonable to attack it from behind. Theoretically, collapse of the cyst should open up the cisterna ambiens, and fluid should escape directly from the lateral ventricle into the subarachnoid space without having to traverse the third ventricle. It should be said, however, that in both of our cases there was evidence of chronic inflammation in the walls of the cyst which had produced local adhesions in the subarachnoid space, and it is possible that these adhesions might limit the efficacy of such an opening. As both of our cases died before they had recovered from the immediate effects of the operation, it is difficult to assess the value of the procedure, but we feel that it is worth a further trial.

It is possible that this process affords an explanation of some cases of hydrocephalus which seem to be arrested spontaneously. If the rupture of the ventricular wall is accompanied or followed by rupture of the pia, the fluid will escape directly into the subarachnoid space and we could speak of a spontaneous ventriculostomy. This event would be more likely in the case of a static or slowly progressive lesion such as benign stricture of the aqueduct than in the case of a neoplastic process.

\section{REFERENCES}

Childe, A. E. and McNaughton, F. L. (1942). Arch. Neurol. Psychiat., Chicago, 47, 768.

Sweet, W. H. (1940). Ibid., 44, 532. 